\title{
Optimizing the Location of Piezoelectric Sensors
}

\author{
I. Plšková* \& Z. Chobola \& M. Matysík \\ Department of Physics, Faculty of Civil Engineering, Brno University of Technology, Brno, Czech Republic \\ * Corresponding author: plskova.i@fce.vutbr.cz
}

DOI: $10.2478 / v 10158-010-0004-2$

\begin{abstract}
Piezoelectric sensors appear to be best suited for picking up acoustic signals thanks to their high sensitivity over a wide frequency range, frequency response stability, design compactness, and reliability. Their design differs from sensor to sensor, depending on the type of the measurement to be carried out. Piezoelectric sensors are manufactured on the basis of crystals and polarized dielectrics. They feature, above all, a very good signalto-noise ratio, a fast response to the load change and a wide range of operating temperatures. Along with the measurements of the noise voltage spectral density, the sensor sensitivity measurements are of high importance not only for the development of acoustic methods but also for the sensor application and, above all, checkout. The present paper deals with our test results of piezoelectric sensors from the following viewpoints: frequency range, response uniformity, sensitivity, and optimum location of a selected sensor with regard to the amplitude of the response signal from a ceramic tile.
\end{abstract}

KEY WORDS: piezoelectric sensor, ceramic tile, Impact-echo method.

\section{INTRODUCTION}

An ideal sensor should be compact, highly sensitive, easy-to-attach to the specimen, low-cost, and of simple design. Furthermore, it should feature a high sensitivity throughout the whole frequency range and a linear response curve. The main requirements concerning the sensor material are: high piezoelectric sensitivity, good mechanical rigidity, and permittivity. Piezoelectric sensors are manufactured on the basis of crystals and polarized dielectrics. The output signal is an electric charge. The design of a piezoelectric sensor is based on the piezoelectric effect which consists of the following: due to a mechanical deformation, electric polarization takes place inside some polycrystalline dielectrics. Image charges subsequently arise on their surface, being able to bind or release real charges on the attached electrodes.

As soon as the voltage vanishes, the dielectric returns to its initial state. Acoustic emission sensors transform acoustic emission wave packets into electric signals. An analysis and visualization of the signal is usually carried out after the measurement is finished, i.e., when the registration cycles of one or several concurrent impulses are completed. If the sensor system detects several acoustic emission packets during a predefined time interval, we can under certain circumstances - assume the impulses to have been produced from a single acoustic emission source (i.e., they are supposed to have the same cause). The emission source can be located by means of two methods in specimens where the lengthwise dimension prevails. In the case of the so-called "point" location, the time differences between the acoustic emission impulse arrival times to different sensors are used to calculate 
the coordinates of the acoustic emission source. If the "zone" location is used, only the sequence in which the acoustic emission impulses arrive at the different sensors is used. An advantage of the "zone" location consists of the fact that the information is sufficient even if the impulses are detected by only a single sensor. In the "zone" location method, each acoustic emission signal source is assigned to a "primary zone", which is determined by the sensor which has been the first to detect the acoustic emission packet.

The sensor output signals are amplified, filtered and saved. The data registration process will start when the magnitude of the amplified and filtered signal exceeds the predefined threshold level. The measurement of an acoustic emission wave packet will be terminated if the measured signal amplitude fails to exceed the predefined threshold level during a preselected time interval.

In the case of acoustic emission, propagating surface tension waves and vibrations, mostly in the frequency range from $20 \mathrm{kHz}$ to $2 \mathrm{MHz}$, are picked up. There are certain types of tasks which require another frequency range. For example, when tracking phase transformation processes, frequencies of the order of $\mathrm{MHz}$ are picked up. The sensor design is therefore different, depending on its intended application. The sensor types most frequently used are as follows: piezoelectric, capacitance, electromagnetic, strain-gauge, mechanical, laser and others.

\section{EXPERIMENT}

\subsection{Piezoelectric sensor frequency characteristics}

Piezoelectric sensors were tested in cooperation with the Department of Physics of the Faculty of Electrical Engineering and Communication Technologies. The objective of the tests consisted of selecting the best suited sensors from the viewpoint of frequency range, sensitivity, and response uniformity. Sensors made by the following manufacturers were tested: Vibra Metrics, Physical Acoustic Corporation and Sedlak. The noise characteristic (noise voltage spectral density versus frequency plot) measuring apparatus comprises of the acoustic emission sensor under investigation, a preamplifier, an amplifier, an oscilloscope intended to measure the rms value of the amplified signal, and, finally, a PC, intended to record and further process the data measured. Figures 1 through 6 show the noise frequency characteristics of PICO 1, PICO 2, Sedlak 7, Sedlak 10, Vibra Metrics 501, Vibra Metrics 516 sensors.

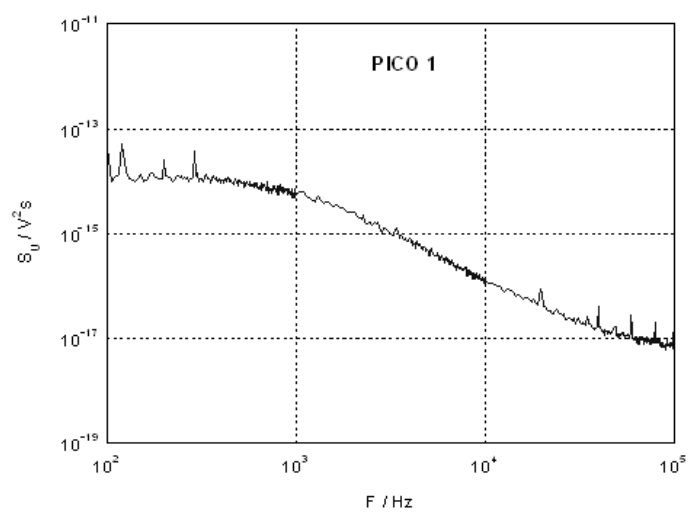

Figure 1: The noise frequency characteristics of sensor PICO 1.

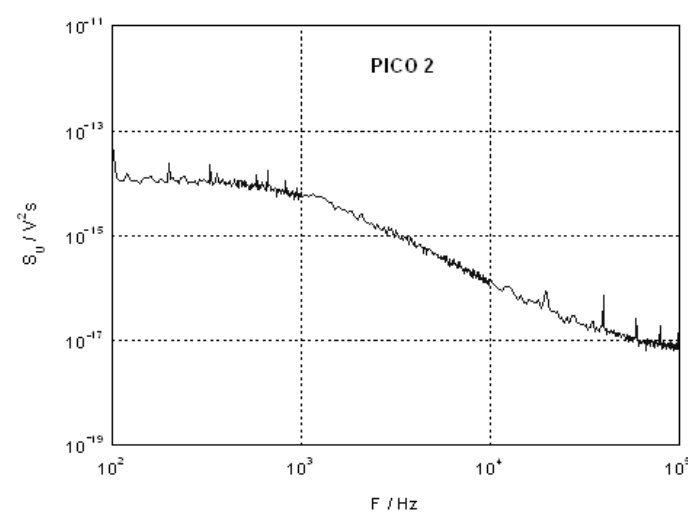

Figure 2: The noise frequency characteristics of sensor PICO 2. 


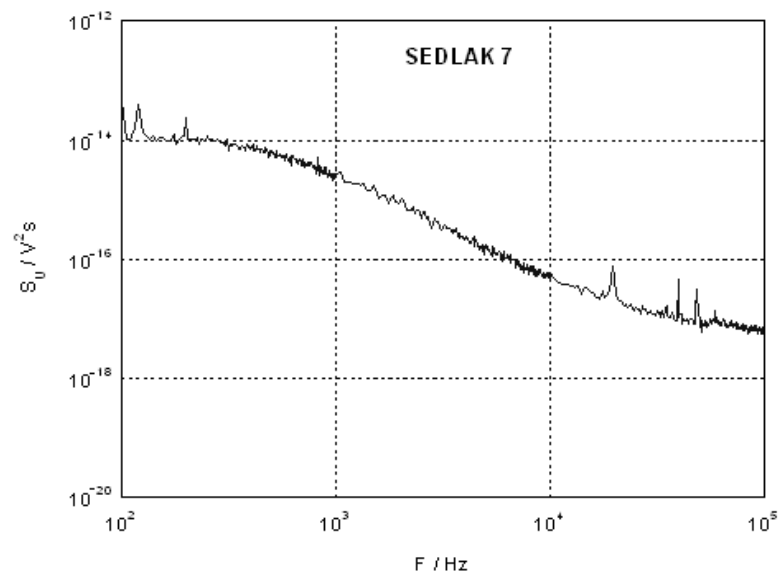

Figure 3: The noise frequency characteristics of sensor SEDLAK 7.

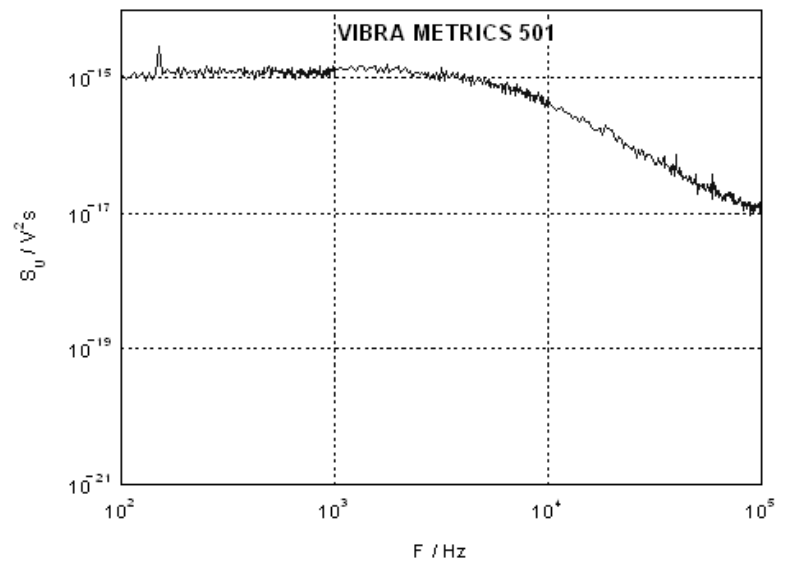

Figure 5: The noise frequency characteristics of sensor VIBRA METRICS 501.

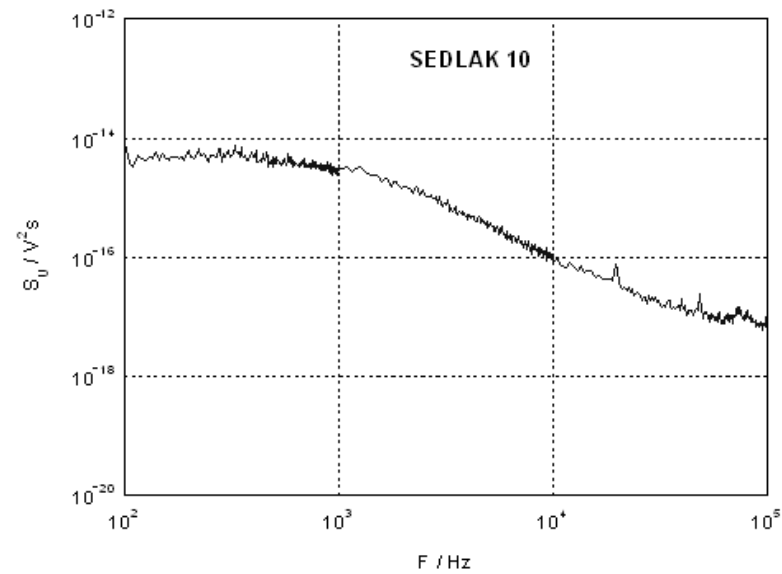

Figure 4: The noise frequency characteristics of sensor SEDLAK 10.

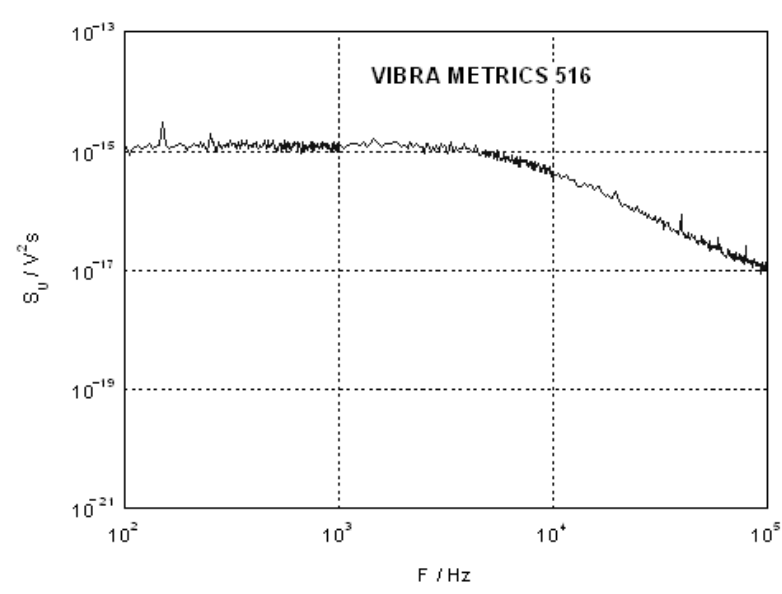

Figure 6: The noise frequency characteristics of sensor VIBRA METRICS 516.

\subsection{Signal amplitude versus sensor position}

To find the optimum sensor position, we studied experimentally the distribution of the readout signal amplitudes throughout the tile surface. This study's results provide information on the best position of the sensor in the tile surface for subsequent experiments. A single specimen of dimensions $30 \times 30 \mathrm{~cm}$ has been selected from the batch of intact ceramic tiles. A line grid was drawn in the surface of the ceramic tile, see Fig. 8. Sedlak type sensors were placed sequentially at different specimen surface grid points. Fig. 7 shows in detail how a Sedlak type piezoelectric sensor is fastened to the ceramic tile surface. Bees wax served as interface between the sensor and the specimen. The measuring point spacing was $1.5 \mathrm{~cm}$. The tile side edge measuring point spacing was $1.5 \mathrm{~cm}$, too. 


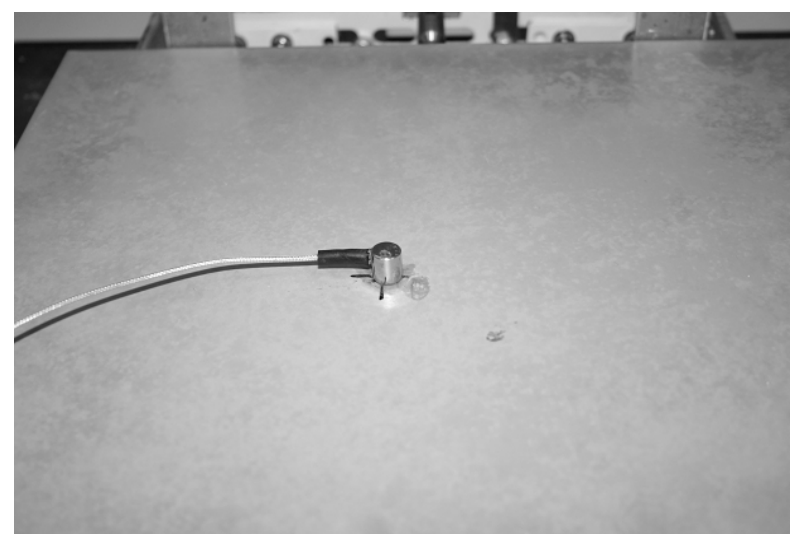

Figure 7: Detailed view of the sensor (SEDLAK) fastening method to the ceramic tile surface.

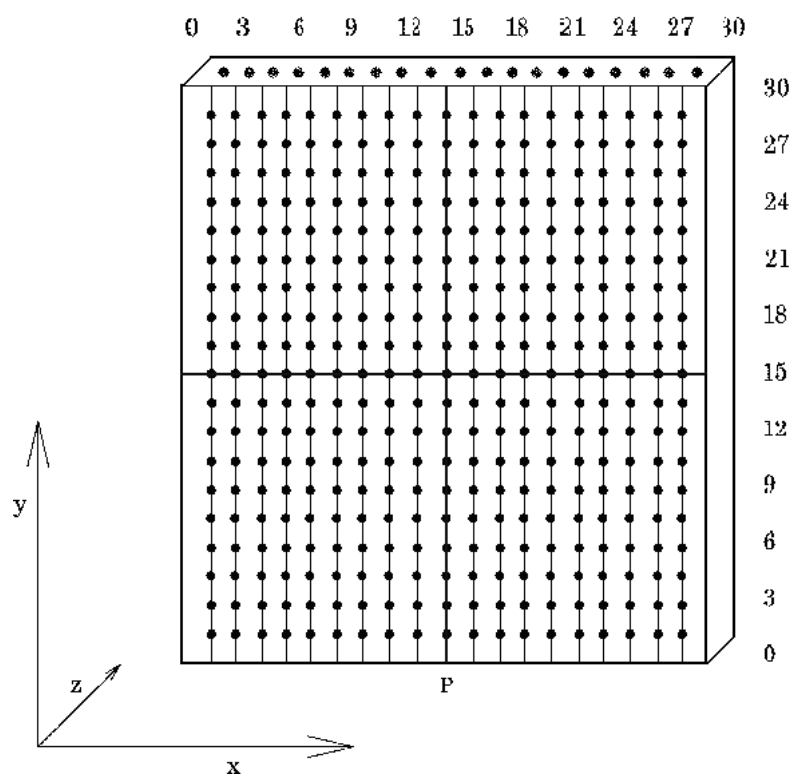

Figure 8: Measuring point distribution over the ceramic tile surface.

The exciting impulse was generated by means of a hammer blow, acting from a constant height and at a defined point of application, for the sake of ensuring identical experiment conditions. The impulse application point $\mathrm{P}$ was selected to be in the middle of the specimen side edge. Piezoelectric sensors, attached to the tile surface at designated points, were used to pick up the tile response to the exciting impulse. A digital oscilloscope was used to record and visualize the response voltage, which was further processed by means of special software.

The distribution of the response signal amplitudes over the tile surface is shown in the diagram of Fig. 9. Figure 10 shows the waveform as determined from the response signal amplitude being picked up at the tile side edge. 


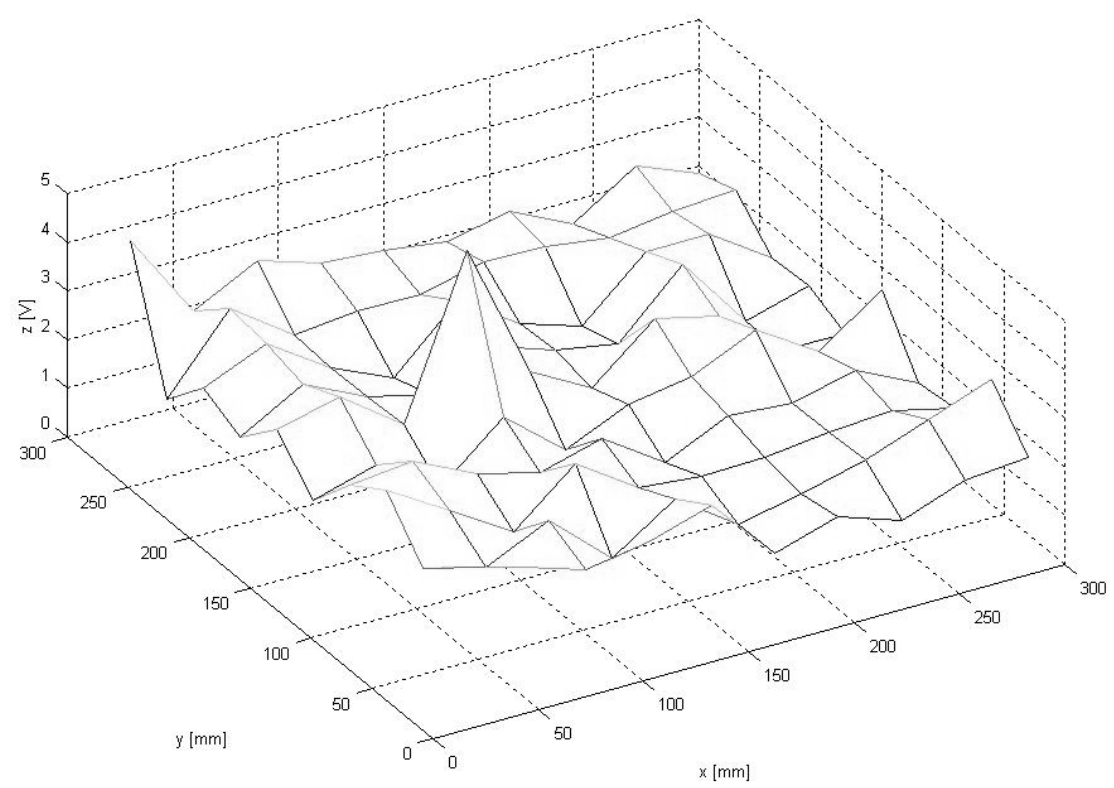

Figure 9: Distribution of amplitudes over the ceramic tile surface.

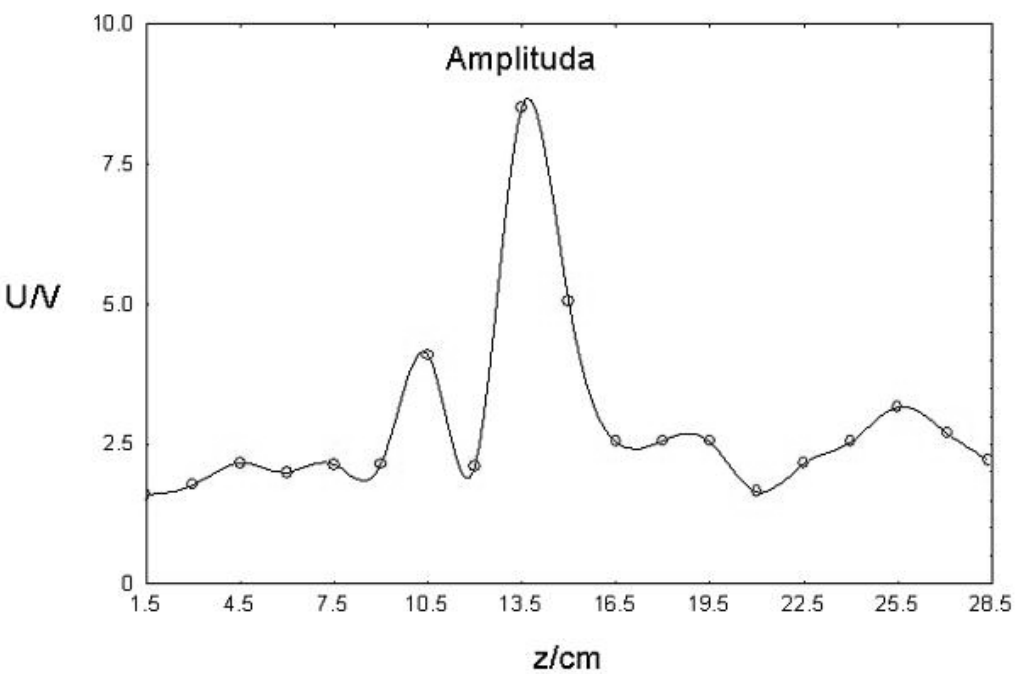

Figure 10: Waveform of a flexure wave at the ceramic tile side edge.

\section{SUMMARY AND CONCLUSIONS}

Following conclusions can be derived from our results:

- $\quad$ Based on our tests of piezoelectric sensors manufactured by Vibra Metrics, Physical Acoustic Corporation and Sedlak, we have selected Sedlak type piezoelectric sensors as the best suited ones, thanks particularly to their high sensitivity and a flat frequency response in the range from $100 \mathrm{~Hz}$ to $50 \mathrm{kHz}$. 
- An experimental study of the acoustic emission signal distribution was carried out in order to find the optimum sensor position in the ceramic tile surface and side edge. Based on this study, information about the optimum sensor position was gained. To reach the highest sensitivity, the sensor was placed at a point of coordinates $x=12 \mathrm{~cm}, \mathrm{y}=18 \mathrm{~cm}$, and, for side edge sensing, at $\mathrm{z}=13,5 \mathrm{~cm}$, in both cases on the surface of a tile of dimensions $30 \times 30 \mathrm{~cm}$. Identical measurements were also carried out on ceramic tiles of dimensions 33 x $33 \mathrm{~cm}$. The best sensor position was $\mathrm{x}=18 \mathrm{~cm}, \mathrm{y}=16.5 \mathrm{~cm}$ for tile surface pick-up and $\mathrm{z}=16.5 \mathrm{~cm}$ for tile side edge pick-up.

- The above mentioned results are going to be used to determine the sensor positions in ceramic tile frost resistance testing experiments.

\section{ACKNOWLEDGEMENTS}

This research has been supported by the Ministry of Education of the Czech Republic, under contract MSM0021630519 and by project of GACR No.103/09/P247.

\section{REFERENCES}

Plšková, I.: 2006. Využití frekvenční inspekce pro posouzení mrazuvzdornosti keramické dlažby: disertační práce. Brno: Vysoké učení technické v Brně, Fakulta stavební, 2006. $117 \mathrm{~s}$.

Serridge M., Licht T.R., 1987. Piezoelectric Accelerometer and Vibration Preamplifier Theory and Application Handbook, Denmark, 1987.

Kazakov V.,P. A. Johnson P. A., 2002. Modulation Acoustic Method of Crack Location. $16^{\text {th }}$ International Symposium on Nonlinear Acoustics Moscow, Russia August 2002.

Majzner J., 2003. Citlivost a šum piezoelektrických snímačů akustické emise, In Proc. Of the Workshop NDT CMC 2003 Non-Destructive Testing of Civil Engineering Structures and Constructions, Czech Republic, ed. by Technical University of Brno, 2003,ISBN 80-7204-318-8.

Yong-Dong Li, Kang Yong Lee, 2009. Fracture analysis on the arc-shaped interface in a layered cylindrical piezoelectric sensor polarized along its axis. Engineering Fracture Mechanics, Volume 76, Issue 13, September 2009, Pages 2065-2073, ISSN 00137944. 